\title{
From Best Evidence to Best Practice: Enteral Nutrition from Continuous Nasal Feeding in Stroke Patients
}

This article was published in the following Dove Press journal: International Journal of General Medicine

\author{
Lijuan Sheng' \\ Lihong Yin' \\ Dezhen Peng' \\ Liping Zhao ${ }^{2}$
}

'Department of Neurology, The Second Xiangya Hospital, Central South University, Changsha, Hunan 4I00II,

People's Republic of China; ${ }^{2}$ Department of Nursing, The Second Xiangya Hospital, Central South University, Changsha, Hunan 4I00II, People's Republic of China
Correspondence: Liping Zhao Department of Nursing, The Second Xiangya Hospital, Central South University, Changsha, Hunan 4100II,

People's Republic of China

$\mathrm{Tel} / \mathrm{Fax}+86$ 73I-8529-4072

Email zhaolp0818@csu.edu.cn
Background: Best evidence regarding enteral nutrition from continuous nasal feeding in stroke patients is limited. The aim of this study was to explore the best evidence of continuous nasal feeding in stroke patients and translate the evidence into clinical practice. Methods: This study utilized the standard procedures of the Joanna Briggs Institute (JBI) evidence-based nursing centers' clinical evidence-practice application system. The baseline assessment of stroke patients in the neurology ward was conducted. A pre- and post-implementation audit approach was used in this study and adopted the Getting Research into Practice program. We analyzed the compliance of nurses with best practice and its impact on patients' gastrointestinal function and complications, aspiration, aspiration pneumonia, nurses' daily workload of nasal feeding, and the length of hospitalization before and after implementing the evidence-based strategies.

Results: After application of the evidence-based strategies, nurses' compliance with best practice was improved. The incidence of patients' gastrointestinal complications including vomit $\left(\chi^{2}=5.195, \mathrm{P}=0.023\right)$, palirrhea $\left(\chi^{2}=4.216, \mathrm{P}=0.039\right)$, diarrhea $\left(\chi^{2}=4.514, \mathrm{P}=0.042\right)$, constipation $\left(\chi^{2}=5.535, \mathrm{P}=0.035\right)$ and gastric retention $\left(\chi^{2}=4.541, \mathrm{P}=0.042\right)$ decreased significantly after the application of the best evidence. The working time of nurses undergoing nasal feeding decreased from $23.71 \pm 3.22 \mathrm{~min}$ to $7.73 \pm 1.14 \mathrm{~min}(\mathrm{P}=0.000)$ and the length of patient's hospitalization decreased from $35.63 \pm 4.45$ days to $35.00 \pm 3.70$ days $(\mathrm{P}=0.534)$. The rate of aspiration, aspiration pneumonia did not show a significant difference after implementation of the evidence-based strategies.

Conclusion: The results revealed that the evidence-based practice of continuous nasal feeding in stroke patients is an effective method to improve nursing quality and reduce gastrointestinal complications, which was worthy of clinical application.

Keywords: stroke, nasal feeding, evidence-based nursing, best evidence, complications

\section{Introduction}

Nutritional supportive therapies, as an important measure for the treatment of critically ill patients, are divided into parenteral nutrition (PN) and enteral nutrition (EN). EN generally refers to the nutritional therapy in which liquid formulations or mixed foods are delivered to the gastrointestinal tract to supplement or provide all the calorie needs of the individual through a feeding tube or mouth. ${ }^{1}$ Nasal feeding is one of the main ways of $\mathrm{EN}$, and it is an important treatment measure to improve the prognosis of critically ill patients. It can maintain the function of the gastrointestinal tract, reduce infectious complications, and shorten hospitalization time compared to PN. ${ }^{2}$ Methods 
of nasal feeding mainly included continuous (continuously pumped through the nutrition pump for 24 hours), cyclic (through the nutrition pump cycle, less than 24 hours a day), intermittent (every 4 to 6 hours per time, each time continuous 20 to $60 \mathrm{~min}$ ) and bolus feeding (through gravity or syringe to complete nasal feeding in a very short time, several times a day). ${ }^{3}$ Stevens et $\mathrm{al}^{4}$ found that diarrhea caused by intermittent nasal feeding occurred more frequently and lasted longer than continuous nasal feeding in the study of nasal feeding for trauma patients, and intermittent nasal feeding caused reflux aspiration more often. In addition, McClave et $\mathrm{al}^{5}$ found that continuous nasal feeding was more beneficial for critically ill patients. Metanalyses have shown that continuous pump nasal feeding could reduce the incidence of enteral nutrition-related complications, and it was better than intermittent nasal feeding in terms of safety. ${ }^{6,7}$ However, due to the low level of literature evidence grade in these studies, there are still limitations in its clinical application. Nevertheless, some studies also suggested that intermittent nasal feeding did not increase the incidence of nasal feeding complications, and in the effect on the gastric acid secretion and $\mathrm{pH}$ value, it was less than that of continuous nasal feeding. ${ }^{4}$ Therefore, there is still controversy and a lack of best evidence about which nasal feeding method is the most effective and reliable. This study summarized the best evidence of nasal feeding and applied it to the clinical practice of stroke patients in the acute setting in the department of neurology, in order to optimize the nursing norms of nasal feeding, reduce the incidence of adverse complications and improve the quality of nursing.

\section{Methods}

\section{Study Design and Population}

The study was conducted to stroke patients in the department of neurology, the Second Xiangya Hospital of Central South University, Changsha, Hunan, China. Before and after the application of the evidence, 12 clinical nurses were included in the department of neurology. All of them were registered nurses, working in the neurology department for 2-20 years, with an average of $8.08 \pm 5.70$ years; and 11 of them with a bachelor's degree, 1 with master's degree. Before the application of the evidence, 38 stroke patients were included and 125 episodes of nasal feeding were performed. After the application of the evidence, 30 patients were included and 60 episodes nasal feeding was performed. The baseline characteristics such as age, gender, nation, marital status, education, medical payment mode, and Glasgow Coma Scale (GCS) score were collected in stroke patients. The criteria for inclusion of patients were as follows: (1) ischemic stroke patients according to the diagnostic criteria revised by the fourth National Conference on Cerebrovascular Diseases and finally diagnosed by CT or MRI; (2) dysphagia and water swallow test $\geq 3$ grade; (3) $\geq$ 18 years old; (4) EN was applied within 48 hours after admission. The exclusion criteria including: (1) intestinal obstruction, active gastrointestinal bleeding, severe intestinal infection, diarrhea, shock, acute pancreatitis; (2) gastrointestinal failure, severe dyspepsia or poor absorption, severe heart, liver, and kidney dysfunction, pneumonia or suspected pneumonia. Termination criteria: (1) unable to complete the intervention; (2) nasal feeding time $<7$ days. This study acquired the ethics approval from the medical ethics committee of the Second Xiangya Hospital of Central South University. All the patients or the patient's relatives and nurses agreed to join the research and signed the informed consent. This study was conducted in accordance with the declaration of Helsinki.

\section{Evidence Retrieval}

\section{Establishment of the Question}

Evidence-based questions were formed using PIPOST $^{8}$ model. P (Population): Stroke patients with enteral nutrition support therapies; I (Intervention): Continuous nasal feeding measures; $\mathrm{P}$ (Professional): physicians and nurses in department of neurology; O (Outcome), $\mathrm{O}_{1}$, Nurse's compliance and workload, $\mathrm{O}_{2}$, gastrointestinal function and complications (vomit, palirrhea, diarrhea, constipation, gastric retention; $\mathrm{O}_{3}$, aspiration and aspiration pneumonia; $\mathrm{O}_{4}$, the length of hospitalization); S (Setting): department of neurology. $T$ (Type of evidence): Recommendation practice, evidence summary, guidelines and systematic reviews.

\section{Search for Evidence}

The time span of the data was from the establishment of the database to October 2018. Database including: China Guide Network; China Biomedical Literature Database (CBM); Fudan evidence-based Nursing Center Database; National Guideline Clearinghouse (NGC); Guidelines International Network (GIN); BMJ Best Practice; Cochrane Library; PubMed; Cumulative Index to Nursing and Allied Health Literature (CINAHL). Keywords including: enteral nutrition, nasogastric feeding, tube feeding, nasogastric tube feeding, enteral feeding pump, enteral nutrition pump, continuous pump feeding, intermittent bolus, intermittent nasogastric feeding, intermittent tube feeding. 


\section{Criteria for Inclusion and Exclusion of Evidence}

The inclusion criteria of evidence resources in this practice were decision support systems, clinical practice guideline reports, evidence summary, and systematic review. Exclusion criteria included all kinds of original research.

\section{The Results of the Literature Search}

A total of 315 articles were searched. After screening, 288 articles were excluded, of which 220 were inconsistent with the subject, 88 cannot find the original articles, and finally, 7 were initially included. After the final screening, 6 articles were included in the evidence resources of this project, including 3 systematic reviews ${ }^{6,7,9}$ (2 CBM and 1 Cochrane Library) and 3 clinical guidelines ${ }^{10-12}$ (1 NGC, 1 GIN1, and 1 China Guide Network). One updated guideline of the European Society of Clinical and Metabolic (ESPEN) for nutritional support treatment for critically ill patients in 2018 was excluded since the ESPEN guidelines provide the best medical nutritional therapy to critically ill patients, define how to assess the nutritional status of an ICU patient and particular conditions frequently observed in intensive care such as patients with dysphagia, frail patients, multiple trauma patients, abdominal surgery, sepsis, and obesity are discussed to guide the practitioner toward the best evidence-based therapy, which there were some limitations in the application of evidence in this study.

\section{Evaluation Criteria for the Quality of Evidence}

Articles meeting inclusion criteria were appraised for methodological quality independently by two nurses, who were trained in evidence-based nursing. Any inconsistency was resolved by consultation until a consensus was reached. ${ }^{13}$ We followed the update of the clinical guidelines research and evaluation system (AGREE II) ${ }^{14}$ in 2012 to comprehensively judge the recommended levels of the guidelines. At the same time, the JBI quality evaluation tool ${ }^{15}$ was used to evaluate the quality of the systematic evaluation, best practices, and evidence summary. For evidence derived from JBI, the results of its evidence rating and recommendation level were directly applied. In addition, for the evidence that did not come from JBI, the 2014 version of JBI evidence pre-classification and evidence recommendation level system was adopted.

\section{Summary of Evidence}

Draft recommendations were developed based on the included evidence. After consultation and discussion among one evidence-based nursing expert, two nasal feeding experts, and two clinical nursing managers, the evidence was divided into six topics including: a nursing group of nasal feeding (A multi-disciplinary nutrition support group); The patient's condition must be evaluated before choosing a certain method of nasal feeding; nasal feeding posture; nasal feeding checking; special nursing; and complications monitoring. The extracted evidence was classified independently by two researchers, and any inconsistency was resolved by consultation until a consensus was reached.

\section{Developing Standard Audit Criteria of the Evidence} According to the (FAME) ${ }^{16}$ the evidence including its feasibility, appropriateness, meaningfulness and effectiveness were audited. All retrieved B-level and above evidence was applied in this study. In addition, the evidence application project team has developed six standard audit criteria via FAME. Standard 1, nurses were aware of the importance of continuous nasal feeding and followed its standard procedures; Standard 2, nurses evaluated patients clinical situation before nasal feeding; Standard 3, nurses performed nasal feeding for patients rather than other medical staff; Standard 4, nurses could evaluate and deal with the patient's adverse reactions or complications correlated with nasal feeding timely; Standard 5, nurses provided oral care for nasal feeding patients; Standard 6, nurses inspected and maintenance the nutrition pump regularly.

\section{Clinical Application of Evidence Data Collection}

During the working day, two graduate students trained in evidence-based medicine were responsible for data collecting. One nurse and one trainee nurse were scheduled for data collecting on weekends and holidays. The night work nurse was assigned for collecting data at night and checked the information in the morning of the next day. A trainee nurse with a regular shift was arranged as an observer. The observation ended immediately after the nasal feeding tube was removed. The methods of data collection included the following three items:

\section{Field Observation Method}

Using the single-blind method, the nurses with fixed shifts (worked at the same time) were arranged as observers every day. The nurses were trained by the permanent staff in the quality audit team. The significance of the project, the observed contents, and the attention points were informed. Whether the nurses carried out continuous 
nasal feeding in accordance with the audit criteria were observed and recorded.

\section{Quality Audit}

The collected data, including the basic characteristics such as the age of the patients, the time of admission, the time of discharge, the time of nurses' nasal feeding operation, the occurrence of gastrointestinal complications were reviewed.

\section{Barriers to Best Practice}

The baseline data of 12 nurses and 38 patients who met the inclusion criteria were audited from August 13 to November 19, 2018. Through the results of nurses compliance before application of the best evidence, we found that the main obstacles to the implementation of evidence included: (1) The nurse was lack of evidence-based nursing awareness; (2) No relevant continuous nasal feeding system and guidelines in neurology departments; (3) the choice of continuous nasal feeding methods were mainly based on clinical experience rather than evidence-based evidence. In response, the evidence application group has developed the following innovative approaches:

\section{Strategy I: Evidence-Based Nursing Training and Assessment for Nurses}

In the daily process of nasal feeding, nurses did not know the evidence-based evidence. They mainly relied on clinical experience. In addition, they did not know that the patient's condition needed to be specifically assessed when choosing nasal feeding procedures. The solution adopted by this group was to carry out evidence-based training and education on continuous nasal feeding rules and regulations for all nurses in the neurology department. This kind of training and education was presented in the way of multimedia teaching. The knowledge of nurses was evaluated before and after teaching, and the effect of nurse training was confirmed by asking questions in the morning and pushed this in the WeChat (a Chinese multi-purpose messaging, social media) group of nurses.

\section{Strategy 2: A Standardized Nasal Feeding Process Was Developed}

At present, there were no standard nasal feeding procedures and regulations in the neurology department of this study. The solution was to establish and improve the procedures and regulations through the related evidence-based resources. After that, the evaluation criteria were established as the basis for the effect of nurses' nasal feeding training and daily inspection of nurses' implementation. At the same time, the workflow of nasal feeding was introduced among nurses, and the time of nasal feeding operation was defined. In addition, the management of continuous nasal feeding has also been the daily duties of nurses.

\section{Strategy 3: Strengthen Continuous Nasal Feeding Training}

In the past, the traditional intermittent nasal feeding method was used in the training of nurses, so that they were not clear about the purpose and process of continuous nasal feeding. The solution was to shoot a video of continuous nasal feeding based on evidence and send it to the WeChat group of nurses, which was used for them to learn. After that, an assessment was conducted on each nurse to ensure that they had mastered the evidence-based method of continuous nasal feeding.

\section{Re-Audit After the Application of the Evidence}

After the evidence-based continuous nasal feeding evidence was applied and practiced in clinical, a study of 12 nurses and 30 patients who met the inclusion criteria was completed from December 11, 2018, to February 18, 2019.

\section{Effectiveness Evaluation Nurses' Compliance with an Evidence-Based Continuous Nasal Feeding}

An audit sheet used to record the implementation of each item was self-designed according to the constructed audit standards. The sheet was also used to analyze nurses' compliance with evidence-based criteria. If the nurse completed the item of audit standard, marked " $\sqrt{ }$ " in the space, if not, marked " $\times$ ". In addition, if the criterion was not observed, it needed to be recorded or explained. The frequency of nurses on the completion of each item of evidence-based criteria was counted separately.

\section{The Gastrointestinal Complications of Nasal Feeding} The complications included vomit, palirrhea, diarrhea, constipation, and gastric retention. Vomit is the involuntary, forceful expulsion of the contents of one's stomach through the mouth and sometimes the nose. Palirrhea is defined as no symptoms of choking and coughing before nasal feeding but choking or wheezing and reflux in the process of nasal feeding. Diarrhea means that the patient defecates more than 3 times a day. Constipation is thought of as infrequent bowel movements, usually less than 3 stools per week. In this experiment, constipation is defined as having no defecation within 3 days. Gastric retention refers to the aspiration of gastric contents of the patient 
every 4 hours through the nasal feeding tube. If the amount of gastric contents extracted exceeds $200 \mathrm{~mL}$, the patient occurred gastric retention.

\section{Aspiration and Aspiration Pneumonia}

Aspiration refers to the countercurrent of stomach contents into the pharynx and trachea. Aspiration pneumonia means that the patient has an obvious history of aspiration and the chest X-ray examination of the patients showed that there were signs of infection in the lung compared to before. Or patients with two or more of the following manifestations, including fever, body temperature above $38.5^{\circ} \mathrm{C}$; chest auscultation indicated rales; cough purulent sputum or sputum volume significantly increased; white blood cell count or neutrophil count increased; sputum culture was positive.

The Workload of Nurses on Nasal Feeding

To record the time spent by nurses on nasal feeding for each patient every day.

The Length of Hospitalization

The hospitalization days of the patient was recorded.

\section{Statistical Methods}

EpiData 3.1 was used for data entry and management, and the data entry quality was checked by the double data entry verification method. Data were analyzed using SPSS version 22. Descriptive analyses were performed using mean, standard deviation and frequency. $\chi^{2}$ test or Fisher's exact test was used to compare the incidence of nasal feeding complications and aspiration and aspiration pneumonia before and after the application of evidence. T-test was used to compare the nutritional index of patients, the workload of nurses and the length of stay of patients before and after the application of evidence. A $P$ value of less than 0.05 was considered statistically significant.

\section{Results}

\section{Demographic Characteristics of the Stroke Patients}

Based on the inclusion and exclusion criteria, a total of 68 participants were selected for final data analysis. The average age of 30 observation group participants was $61.71 \pm 10.17$ years old, and about 21 of them were male. The results showed that there was no difference among age, gender, nation and any other characteristics in the observation group compared with the control group $(\mathrm{P}>0.05)$. The details of these stroke patients' features are shown in Table 1.

\section{Summary of the Best Evidence of Continuous Nasal Feeding}

A consensus expert opinion about the best evidence for nasal feeding in stroke patients was finally compiled and used as a basis for decision-making after repeated consultation, induction, and modification (Table 2).

\section{Nurses' Compliance Before and After the Application of the Best Evidence}

After the application of the evidence, the compliance rate of standard 1 increased from $20 \%$ to $100 \%$ and standard 2, 3 increased from $0 \%$ to $100 \%$. In addition, the compliance rate of standard 4 increased from $71.2 \%$ to $100 \%$ and standard 5 increased from $44 \%$ to $100 \%$. Besides, the compliance rate of standard 6 increased from $21.6 \%$ to $100 \%$. The compliance of nurses' evidence-based behavior was significantly improved (Table 3).

\section{The Incidence of Gastrointestinal Complications Before and After the Application of Evidence}

After the application of the evidence, the gastrointestinal complications including vomiting $(\chi 2=5.195, \mathrm{P}=0.023)$, palirrhea $\left(\chi^{2}=4.216, \quad \mathrm{P}=0.039\right)$, diarrhea $\left(\chi^{2}=4.514\right.$, $\mathrm{P}=0.042)$, constipation $(\chi 2=5.535, \mathrm{P}=0.035)$, gastric retention $(\chi 2=4.541, \mathrm{P}=0.042)$ were lower than that before the evidence. The difference was statistically significant $(\mathrm{P}<0.05)$ (Table 4).

\section{Incidence of Aspiration and Aspiration Pneumonia in Patients Before and After the Application of Evidence}

After the application of evidence, the incidence of aspiration $(\mathrm{F}=2.478, \quad \mathrm{P}=0.249)$ and aspiration pneumonia $(\mathrm{F}=1.627, \mathrm{P}=0.500)$ in patients with nasal feeding was lower than that before the application of evidence, and there was no case after the application of evidence, but the difference was not statistically significant $(\mathrm{P}>0.05)$, as shown in Table 5 .

\section{The Workload of Nurses on Nasal Feeding and Hospitalization Days Before and After the Application of Evidence}

After the application of the evidence, the time of the nurses spent on nasal feeding was decreased from 23.71 $\pm 3.22 \mathrm{~min}$ to $7.73 \pm 1.14 \mathrm{~min}$, and the difference was 
Table I Demographic Characteristics of Stroke Patients

\begin{tabular}{|c|c|c|c|c|c|}
\hline Items & Characteristics & Observation Group $(n=30)$ & $\begin{array}{l}\text { Control Group } \\
(n=38)\end{array}$ & $\chi^{2}(\mathrm{t})$ & $\boldsymbol{P}$ \\
\hline Age & Years & $61.71 \pm 10.17$ & $62.7 I \pm 7.70$ & -0.207 & 0.839 \\
\hline Gender & $\begin{array}{l}\text { Male } \\
\text { Female }\end{array}$ & $\begin{array}{l}21 \\
9\end{array}$ & $\begin{array}{l}26 \\
12\end{array}$ & 0.020 & 0.889 \\
\hline Nation & $\begin{array}{l}\text { Han nationality } \\
\text { Minority }\end{array}$ & $\begin{array}{l}28 \\
2\end{array}$ & $\begin{array}{l}34 \\
4\end{array}$ & 0.310 & 0.577 \\
\hline Marital status & $\begin{array}{l}\text { Married } \\
\text { Unmarried }\end{array}$ & $\begin{array}{l}28 \\
2\end{array}$ & $\begin{array}{l}35 \\
3\end{array}$ & 0.037 & 0.847 \\
\hline Education & $\begin{array}{l}\text { Elementary or Junior } \\
\text { Senior } \\
\text { College or above }\end{array}$ & $\begin{array}{l}18 \\
11 \\
1\end{array}$ & $\begin{array}{l}27 \\
8 \\
3\end{array}$ & 2.365 & 0.306 \\
\hline Medical payment mode & $\begin{array}{l}\text { Health insurance/Commercial } \\
\text { insurance. } \\
\text { Self-paying }\end{array}$ & $\begin{array}{l}28 \\
2\end{array}$ & $\begin{array}{l}37 \\
1\end{array}$ & 0.044 & 0.834 \\
\hline GCS score & & $11.57 \pm 4.39$ & $10.50 \pm 4.59$ & 0.429 & 0.676 \\
\hline
\end{tabular}

statistically significant $(\mathrm{P}<0.05)$. The hospitalization days were decreased from $35.63 \pm 4.45$ days to $35.00 \pm 3.70$ days, and the difference was not statistically significant $(\mathrm{P}>$ 0.05), as shown in Table 6.

\section{Discussion}

\section{Feasibility Analysis of Clinical Evidence Applied to Practice}

In this study, the clinical feasibility and suitability were fully considered in the application of evidence. After strict literature screening and quality evaluation, three systematic reviews and three clinical guidelines were included. Through the back-toback evaluation and classification of the evidence by two evidence-based nursing training personnel, and screened by experts in this field, the best practice evidence suitable for the clinical situation and patients' wishes was obtained finally, which was scientific and practical.

\section{Application of the Best Evidence of Continuous Nasal Feeding into Practice Can Improve the Condition of the Stroke Patient}

Currently, some researches support that continuous pump nasal feeding could reduce the incidence of nasal feeding complications, and it was better than traditional intermittent nasal feeding in ensuring the safety of nasal feeding. However, there was some clinical heterogeneity among these studies. ${ }^{17}$ In addition, due to the limitation of patients' economic ability and medical operation habits in clinical nursing practice, continuous nasal feeding was not always widely used in clinical practice. Moreover, clinical nursing practice mainly depends on doctors' decision-making or clinical experience and lacks the guidance of evidence-based practice. Based on the evidence-based practice, the latest evidence of continuous nasal feeding was applied to the nursing practice of stroke patients. The incidence of gastrointestinal complications was significantly lower than that before the application of the evidence. In addition, the workload of nurses was reduced. Before the application of the best evidence, the nurses always used intermittent nasal feeding method for stroke patients, so it took a relatively long time for each patient. Besides, nurses were not clear about the requirement and purpose of continuous nasal feeding and the operation was not up to the standard. However, after applying the best evidence, the method adopted by nurses was based on evidence-based medicine, which not only standardized the nasal feeding operation procedure but also shortened the time spent on each patient. Also, the incidence of aspiration and aspiration pneumonia in patients with continuous nasal feeding and the hospitalization days decreased, but the difference was not statistically significant. This may be related to the small sample size. In addition, the length of hospitalization may also be related to many factors such as the severity of the patient's clinical 
Table 2 Summary of the Best Evidence of Continuous Nasal Feeding

\begin{tabular}{|c|c|c|}
\hline Type of Evidence & Content of Evidence & $\begin{array}{l}\text { Recommendation } \\
\text { Degree }\end{array}$ \\
\hline Nursing group of nasal feeding & $\begin{array}{l}\text { A multi-disciplinary nutrition support group should be formed to make } \\
\text { clinical decisions on nutritional support methods, feeding patterns, and } \\
\text { management plans. All staff involved in nasal feeding care should be } \\
\text { educated and trained }\end{array}$ & A \\
\hline \multirow{6}{*}{$\begin{array}{l}\text { The patient's condition must be evaluated } \\
\text { before choosing a certain method of nasal } \\
\text { feeding. }\end{array}$} & $\begin{array}{l}\text { Nutrition pump was used to patients with long-term nasal feeding ( } 2 \text { to } 3 \\
\text { weeks or more). }\end{array}$ & $A$ \\
\hline & $\begin{array}{l}\text { Patients who cannot tolerate intermittent nasal feeding adopted } \\
\text { continuously nasal feeding by a nutrition pump. }\end{array}$ & $A$ \\
\hline & $\begin{array}{l}\text { To use a nutrition pump when nasal feeding is recommended for the } \\
\text { elderly lying in bed patients. }\end{array}$ & A \\
\hline & $\begin{array}{l}\text { Patients with a critical illness or major surgery should use a nutrition } \\
\text { pump at the beginning of nasal feeding. }\end{array}$ & A \\
\hline & $\begin{array}{l}\text { When the viscosity of the nutrient solution is higher, or infusion speed } \\
\text { needs to be strictly controlled or infusing higher dose and higher osmotic } \\
\text { pressure nutrient solution, it is recommended to use a nutrition pump. }\end{array}$ & $A$ \\
\hline & $\begin{array}{l}\text { For patients with normal gastrointestinal function, the nutrient solution } \\
\text { of whole protein standard formula is recommended; dietary fiber can } \\
\text { reduce diarrhea caused by nasal feeding in elderly patients and promote } \\
\text { normal intestinal peristalsis. }\end{array}$ & A \\
\hline Nasal feeding position & $\begin{array}{l}\text { Keep the bed head raised at } 30^{\circ} \text { to } 45^{\circ} \text { during nasal feeding, except for } \\
\text { contraindications. It is recommended that patients remain in a semi- } \\
\text { recumbent position for } 30-60 \text { minutes after nasal feeding. }\end{array}$ & A \\
\hline Nasal feeding checking & $\begin{array}{l}\text { The nutrition pump should adopt the centralized management mode of } \\
\text { specialist responsibility, and the nutrition pump should be calibrated and } \\
\text { maintained regularly to ensure its accuracy. }\end{array}$ & B \\
\hline Special nursing & $\begin{array}{l}\text { For patients with long-term nasal feeding, oral care is recommended } \\
\text { twice a day, and oral care with chlorhexidine is given to mechanically } \\
\text { ventilated nasal feeding patients twice a day to reduce the incidence of } \\
\text { pneumonia. }\end{array}$ & A \\
\hline Complications monitoring & $\begin{array}{l}\text { During nasal feeding, nurses should regularly monitor the occurrence of } \\
\text { gastrointestinal complications (gastric retention, diarrhea, constipation, } \\
\text { reflux), aspiration and aspiration pneumonia. }\end{array}$ & $A$ \\
\hline
\end{tabular}

condition, so it needs to be verified in large sample size in the future.

\section{The Application of the Best Evidence of Continuous Nasal Feeding Effectively Improves the Quality of Nursing}

Some studies have shown that continuous nasal feeding has advantages over intermittent nasal feeding and can effectively improve the quality of nursing. ${ }^{18-20}$ In this study, evidence-based continuous nasal feeding practice was introduced into clinical practice, which can enable nurses to better understand evidence-based nursing and solidify nursing behavior in their daily work. This not only updated nurses' knowledge of evidence-based continuous nasal feeding but also significantly improved their compliance. In addition, through the analysis of obstacle factors, this study further put forward improvement measures and standardized the process of continuous nasal feeding in the hospital. It can standardize the nursing 
Table 3 Compliance of Nurses Before and After the Application of the Best Evidence

\begin{tabular}{|l|l|l|l|l|l|l|l|l|l|l|}
\hline \multirow{2}{*}{ Standard Number } & \multicolumn{3}{|l|}{ Compliance Before Evidence Applied } & \multicolumn{3}{l|}{ Compliance After Evidence Applied } \\
\cline { 2 - 10 } & Case & Y & N & NA & Compliance rate/100\% & Case & Y & N & NA & Compliance rate/ 100\% \\
\hline Standard I & 125 & 25 & 100 & 0 & $20 \%$ & 60 & 60 & 0 & $100 \%$ \\
Standard 2 & 125 & 0 & 125 & 0 & $0 \%$ & 60 & 60 & 0 & $100 \%$ \\
Standard 3 & 125 & 0 & 125 & 0 & $0 \%$ & 60 & 60 & 0 & $100 \%$ \\
Standard 4 & 125 & 89 & 36 & 0 & $71.2 \%$ & 60 & 60 & 0 & $100 \%$ \\
Standard 5 & 125 & 55 & 70 & 0 & $44 \%$ & 60 & 60 & 0 & $100 \%$ \\
Standard 6 & 125 & 27 & 98 & 0 & $21.6 \%$ & 60 & 60 & 0 & $100 \%$ \\
\hline
\end{tabular}

Notes: Y-The nurse performed correctly in completing the examination standard; N- The nurse performed an error in completing the examination standard, NA- No audit criteria were observed.

Abbreviations: Standard I, nurses were aware of the importance of continuous nasal feeding and followed its standard procedures; Standard 2, nurses evaluated patients clinical situation before nasal feeding; Standard 3, nurses performed nasal feeding for patients rather than other medical staff; Standard 4, nurses could evaluate and deal with the patient's adverse reactions or complications correlated with nasal feeding timely; Standard 5, nurses provided oral care for nasal feeding patients; Standard 6, nurses inspected and maintenance the nutrition pump regularly.

Table 4 The Incidence of Gastrointestinal Complications Before and After Application of the Best Evidence

\begin{tabular}{|c|c|c|c|c|c|c|}
\hline Time & Cases & Vomit & Palirrhea & Diarrhea & Constipation & $\begin{array}{l}\text { Gastric } \\
\text { Retention }\end{array}$ \\
\hline Before evidence applied & 38 & 6 & 5 & II & 8 & 12 \\
\hline After evidence applied & 30 & 0 & 0 & 4 & I & 3 \\
\hline$\chi^{2}$ & & 5.195 & 4.216 & 4.514 & 5.535 & 4.541 \\
\hline$P$ & & 0.023 & 0.039 & 0.042 & 0.035 & 0.042 \\
\hline
\end{tabular}

Table 5 The Incidence of Aspiration and Aspiration Pneumonia Before and After Application of the Best Evidence

\begin{tabular}{|l|l|l|l|}
\hline Time & Cases & Aspiration & $\begin{array}{l}\text { Aspiration } \\
\text { Pneumonia }\end{array}$ \\
\hline $\begin{array}{l}\text { Before evidence } \\
\text { applied }\end{array}$ & 38 & 3 & 2 \\
\hline $\begin{array}{l}\text { After evidence } \\
\text { applied }\end{array}$ & 30 & 0 & 0 \\
\hline F & & 2.478 & 1.627 \\
\hline$P$ & & 0.249 & 0.500 \\
\hline
\end{tabular}

practice behavior of nurses and effectively improve the quality of clinical nursing.

To sum up, how to apply the best evidence to clinical practice has been the focus of attention in the field of nursing. Gurzick et $\mathrm{al}^{21}$ indicated that the promotion of evidence application project could improve the evidencebased thinking ability and compliance of clinical nurses, so as to improve the quality of clinical nursing.

\section{Limitations}

When we summarize the evidence, there may be conflicts in the review of evidence-based practice due to the cultural
Table 6 The Workload of the Nurse and the Length of Hospitalization of Patients Before and After the Application of the Best Evidence

\begin{tabular}{|l|l|l|l|}
\hline Time & Case & $\begin{array}{l}\text { Nurse's Daily } \\
\text { Work (min) }\end{array}$ & $\begin{array}{l}\text { Length of } \\
\text { Hospitalization } \\
\text { (d) }\end{array}$ \\
\hline $\begin{array}{l}\text { Before } \\
\text { evidence } \\
\text { applied }\end{array}$ & 38 & $23.7 I \pm 3.22$ & $35.63 \pm 4.45$ \\
\hline $\begin{array}{l}\text { After evidence } \\
\text { applied }\end{array}$ & 30 & $7.73 \pm 1.14$ & $35.00 \pm 3.70$ \\
\hline$t$ & & 25.881 & 0.625 \\
\hline$P$ & 0.000 & 0.534 \\
\hline
\end{tabular}

differences between China and the West, which may lead to the failure of evidence-based practice in clinical application. Therefore, we should consider the localization of evidence in the audit and application of evidence. In addition, the collection of data in this study was limited to one hospital, so the sample size was small. In order to better understand the effectiveness of the evidence-practice, it is also necessary to carry out multicenter, large sample studies and increase research in a patient with other diseases. 
Finally, a major limitation is a bias in the observer's assessment, given that they are aware of the pre-/postintervention study design.

\section{Conclusions}

In this study, evidence was obtained by the evidence-based method, and strict quality evaluation was carried out. Through the implementation of the best evidence of continuous nasal feeding, the compliance of nurses' evidence-based practice was significantly improved and the incidence of complications was effectively reduced. This not only made nurses have a deeper understanding of the evidence-based practice but also promoted the wide promotion of evidence-based nursing practice in the neurology department. In addition, it also provided a reference for the follow-up work of evidence-based nursing and the transformation of evidence.

\section{Data Sharing Statement}

The datasets used and/or analyzed during the present study were availed by the corresponding author on reasonable request.

\section{Funding}

This work was supported by the Clinical Nursing Research Fund Project of the Second Xiangya Hospital. (2018YHL-50).

\section{Disclosure}

The authors report no conflicts of interest for this work.

\section{References}

1. Bankhead R, Boullata J, Brantley S, et al. Enteral nutrition practice recommendations. JPEN J Parenter Enteral Nutr. 2009;33:122-167. doi:10.1177/0148607108330314

2. McClave SA, Martindale RG, Vanek VW, et al. Guidelines for the provision and assessment of nutrition support therapy in the adult critically ill patient: society of Critical Care Medicine (SCCM) and American Society for Parenteral and Enteral Nutrition (A.S.P.E.N.). JPEN J Parenter Enteral Nutr. 2009;33:277-316.

3. Ichimaru S. METHODS of enteral nutrition administration in critically ill patients: continuous, cyclic, intermittent, and bolus feeding. Nutr Clin Pract. 2018;33:790-795.

4. Steevens EC, Lipscomb AF, Poole GV, et al. Comparison of continuous vs intermittent nasogastric enteral feeding in trauma patients: perceptions and practice. Nutr Clin Pract. 2002;17:118-122.
5. McClave SA, Taylor BE, Martindale RG, et al. Guidelines for the provision and assessment of nutrition support therapy in the adult critically ill patient: society of Critical Care Medicine (SCCM) and American Society for Parenteral and Enteral Nutrition (A.S.P.E.N.). JPEN J Parenter Enteral Nutr. 2016;40:159-211.

6. Wang YHYC. Effects of continuous nasogastric feeding on the incidence of complications:a systematic review. $J$ Nurs. 2014;22:83-87.

7. Jianguo Yang JZBY. Effects of enteral feeding pump and intermittent bolus nasogastric feeding on reducing complications of enteral nutrition: a meta-analysis. Chin J Evid Based Med. 2014;2:197-204.

8. Aromataris E, Fernandez R, Godfrey CM, et al. Summarizing systematic reviews: methodological development, conduct and reporting of an umbrella review approach. Int $J$ Evid Based Healthc. 2015;13:132-140. doi:10.1097/XEB.0000000000000055

9. White H, King L. Enteral feeding pumps: efficacy, safety, and patient acceptability. Med Devices (Auckl). 2014;7:291-298.

10. Hu Yanqiu CYWY. Construction of clinical practice guidelines for adult feeding through the nasogastric tube. Chin J Nurs. 2016;2:133141.

11. Gomes F, Hookway C, Weekes CE. Royal College of Physicians Intercollegiate Stroke Working Party evidence-based guidelines for the nutritional support of patients who have had a stroke. J Hum Nutr Diet. 2014;27:107-121.

12. Singer P, Blaser AR, Berger MM, et al. ESPEN guideline on clinical nutrition in the intensive care unit. Clin Nutri. 2019;38:48-79. doi:10.1016/j.clnu.2018.08.037

13. Newhouse RP, Dearholt SL, Poe SS, et al. Johns Hopkins Nursing Evidence-Based Practice Model and Guidelines. Indianapolis, IN: Sigma Theta Tau International Honor Society of Nursing; 2007.

14. Brouwers MC, Kho ME, Browman GP, et al. The Global Rating Scale complements the AGREE II in advancing the quality of practice guidelines. J Clin Epidemiol. 2012;65:526-534. doi:10.1016/j. jclinepi.2011.10.008

15. Duffy ME. The Joanna Briggs Institute: its contribution to evidencebased practice. Clin Nurse Spec. 2005;19:184-186. doi:10.1097/ 00002800-200507000-00007

16. Reynolds S. Evidence-Based Practice: A Critical Appraisal. John Wiley \& Sons; 2008.

17. Lee JS, Auyeung TW. A comparison of two feeding methods in the alleviation of diarrhoea in older tube-fed patients: a randomised controlled trial. Age Ageing. 2003;32:388-393. doi:10.1093/ageing/ 32.4.388

18. Ichimaru S. Methods of enteral nutrition administration in critically ill patients: continuous, cyclic, intermittent, and bolus feeding. Nutr Clin Pract. 2018;33:790-795. doi:10.1002/ncp.10105

19. Shahriari M, Rezaei E, Bakht LA, et al. Comparison of the effects of enteral feeding through the bolus and continuous methods on blood sugar and prealbumin levels in ICU inpatients. $J$ Educ Health Promot. 2015;4:95.

20. Evans DC, Forbes R, Jones C, et al. Continuous versus bolus tube feeds: does the modality affect glycemic variability, tube feeding volume, caloric intake, or insulin utilization? Int J Crit Illn Inj Sci. 2016;6:9-15.

21. Gurzick M, Kesten KS. The impact of clinical nurse specialists on clinical pathways in the application of evidence-based practice. $J$ Prof Nurs. 2010;26:42-48. 


\section{Publish your work in this journal}

The International Journal of General Medicine is an international, peer-reviewed open-access journal that focuses on general and internal medicine, pathogenesis, epidemiology, diagnosis, monitoring and treatment protocols. The journal is characterized by the rapid reporting of reviews, original research and clinical studies across all disease areas. The manuscript management system is completely online and includes a very quick and fair peer-review system, which is all easy to use. Visit http://www.dovepress.com/ testimonials.php to read real quotes from published authors.

Submit your manuscript here: https://www.dovepress.com/international-journal-of-general-medicine-journal 